\title{
Performance of Steel Concrete Steel Sandwich Beam with Varying Shear Connectors
}

\author{
P. Sangeetha* and R. Ashwin Muthuraman \\ Department of Civil Engineering, SSN College of Engineering, Chennai - 603110, Tamil Nadu, India; \\ sangeethap@ssn.edu.in, ashwinvinayak96@gmail.com
}

\begin{abstract}
Steel-Concrete-Steel sandwich structures are made of concrete core sandwiched in between two steel plates, has been usedin port and harbour facilities, submerged tube tunnels, protective structures, building cores, etc. in which resistance against impact and sudden loads is an importance aspect. Objective: To investigate the behaviour of the sandwich beam under flexural loading. The shear connectors varied in the sandwich beam are L-Angle, Channel, Tee section and Headed bolt. The load-deflection, load-strain and load-slip behaviour was plotted and compared with different shear connectors of the sandwich beam. Methods/Analysis: All the sandwich beams were also analysed using finite element software ANSYS. From the study it was concluded that sandwich beam with channel and Tee connectors performed better than the beam with angle and headed stud connectors. Findings: From the load slip behaviour, the stiffness of the different connectors was found. The load carrying capacity of the sandwich beam with Tee and Channel connectors were improved by $70 \%$ compared to angle and headed stud connectors. The maximum deflection found from the analytical models was lesser than the experimental results. The analytical model is found to be stiffer due to rigid connections of the model. Application: The load-strain, load-deflection and load-slip behaviour was also studied. The analytical study was also carried out using ANSYS to compare the results. The conclusion arrived from the study are.
\end{abstract}

Keywords: Load-Deflection Behaviour, Load-Slip Behaviour, Sandwich Beam, Shear Connector, ANSYS

\section{Introduction}

Steel-concrete-steel sandwich structures are widely in use now days. They are made by sandwiching flat steel plates with concrete and shear connectors. Concrete act as central core and composite action between the steel plate and concrete is obtained by providing proper shear connectors. The advantages of the sandwich structures are fast track construction, effective utilisation of materials, higher strength and stiffness, steel plate in the sandwich structures acts as form work, which in turn reduces the cost of construction. This structure provides better resistance against impact and heavy sudden loading. Sandwich structures are normally used port, harbour and underwater constructions like gravity wall, floating platform, offshore components etc. In ${ }^{1}$ have fabricated the composite sandwich beam and studied its flexural behaviour and also compared the experimental results with predicted theoretical model. $\mathrm{In}^{2}$ have studied the steel - concrete - steel sandwich beams analysed using finite element software ABAQUS and compared the results with experimental study. The percentage difference in the results between analytical model and experimental model are low. $\operatorname{In}^{3}$ have proposed a new concept for designing sandwich system using light weight fiber reinforced concrete with new J- hook connector and stated that presence of fibers improves the flexural strength and ductility of the beam. $\operatorname{In}^{4}$ have studied the steel - concrete - steel system using light weight concrete under static and fatigue loading and proposed fatigue design equation for S-N curve generation. In $\frac{5}{}$ have investigated the steel - concrete - steel slab using light weight concrete with J-hook con-

${ }^{*}$ Author for correspondence 
nectors under static loading conditionand also proposed the theoretical model to predict the flexural and punching strength of the slab. $\mathrm{In}^{6}$ have investigated the behaviour of sandwich beam with different mechanical shear connectors and also proposed the design equations to find the minimum spacing between the connectors on order to prevent the local buckling of steel plates and concrete. $\mathrm{In}^{\mathrm{7}}$ have the performance of the sandwich beam interconnected by the channel connectors under static loading and stated that beams were because of flexure and shear. $\operatorname{In}^{8}$ have studied the behaviour of the composite space truss with the proposed shear connector under static loading and concluded that composite action enhanced by using steel flat and bolt as connector.

\section{Experimental Study}

\subsection{Specimen Preparation}

Four sandwich beams of overall dimension of $500 \mathrm{x} 150 \mathrm{x}$ $100 \mathrm{~mm}$ were fabricated using steel flat plate of size $500 \mathrm{x}$ $100 \times 20 \mathrm{~mm}$. The dimensions of the sandwich beam are clearly shown in Figure 1. Four different types of connectors such as angle, bolt, channel and tee were used to give composite action between steel and concrete. Total of five numbers of shear connectors were welded in the steel flat in such a way three in the top plate and two in the bottom plate as shown in Figure 2. The spacing between the connectors is $167 \mathrm{~mm}$. M30 grade of concrete was used to fill in between the steel plate. The mix proportion of concrete used in the sandwich beam was calculated using IS10262:2009 and it was listed in Table 1. The trail mix was prepared and cubes were casted to check the characteristics compressive strength of the concrete. Figure 3 shows the steel plates and shear connectors after welding. Figure 4 shows sandwich beams before testing.

\subsection{Instrumentation}

All the specimens were pasted with strain gauge of $20 \mathrm{~mm}$ at the centre and three dial gauges were used to measure the strain, slip and deflection between concrete and steel. The dial gauge number 1 and 2 were used to measure the slip in the bottom steel plate andin concrete respectively. The central axial deflection in the sandwich beam was measured using dial gauge number 3 which is fixed under the sandwich beam. Figure 5 shows the position of the strain gauge and dial gauges and test set up. The testing of specimen was done using Universal testing machine (UTM) of capacity $60 \mathrm{kN}$. The strain was recorded using five channel digital strain indicator. Figure 6 shows the beam after failure. It is observed that first crack initiated at $70 \%$ of peak load. The crack pattern in the sandwich beam shows that the initiation of crack is from the point of shear connectors present in the bottom steel plate and which is clearly seen in the Figure 6.

Table 1. Mix proportion of concrete

\begin{tabular}{|l|l|l|l|}
\hline Cement & $\begin{array}{l}\text { Fine aggregate } \\
\text { Sand }\end{array}$ & $\begin{array}{l}\text { Coarse aggregate } \\
\text { Gravel }\end{array}$ & W/c \\
\hline 1 & 1.99 & 1.9 & 0.45 \\
\hline 457 & 911 & 872 & 206 \\
\hline
\end{tabular}

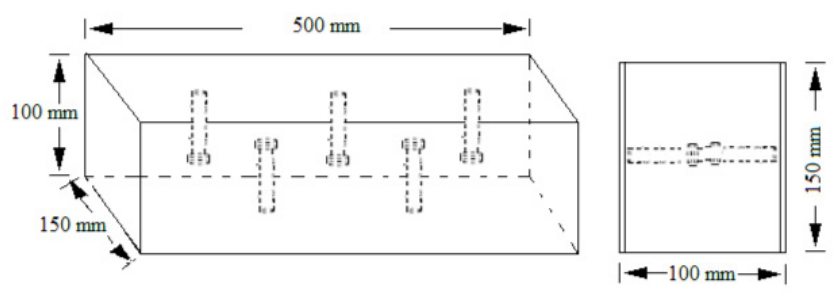

Figure 1. Dimensions of the sandwich beam with stud connector.

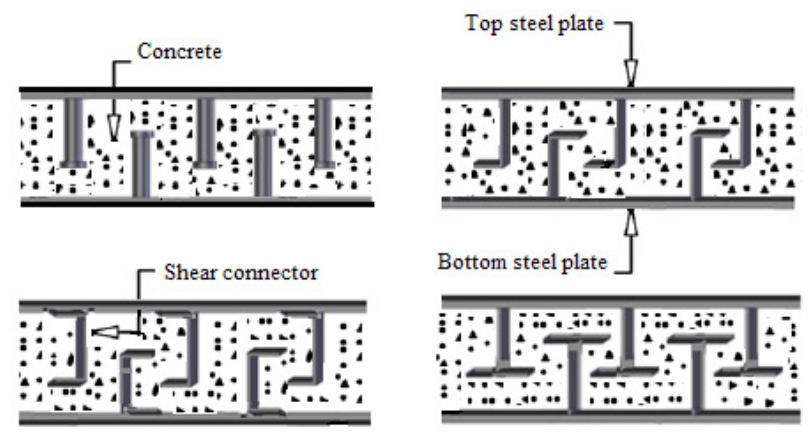

Figure 2. Schematic diagram of the steel concrete steel sandwich beam with different connectors.

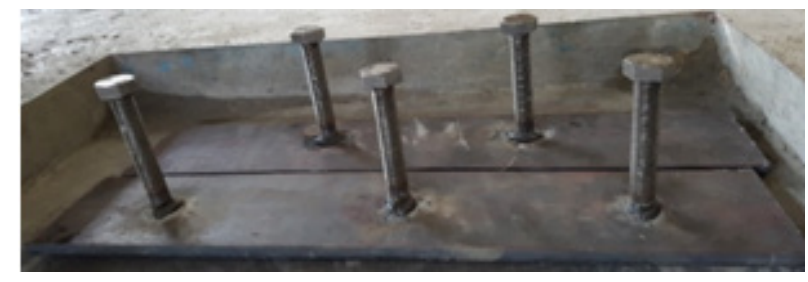

(a)Bolt connector 


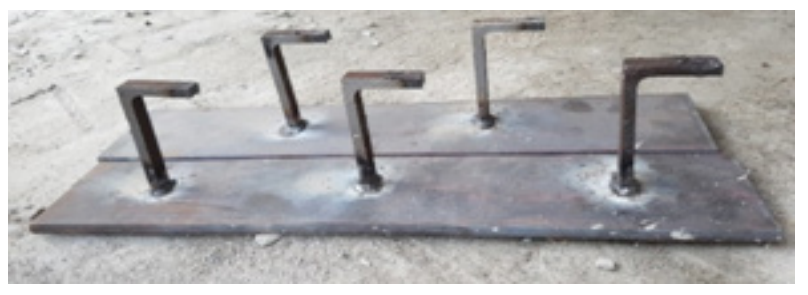

(b) Angle connector

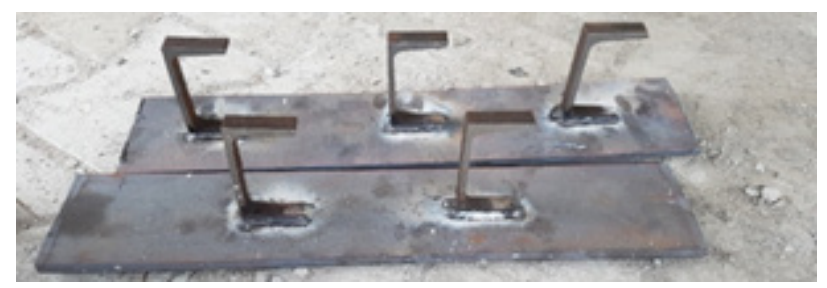

(c) Channel connector

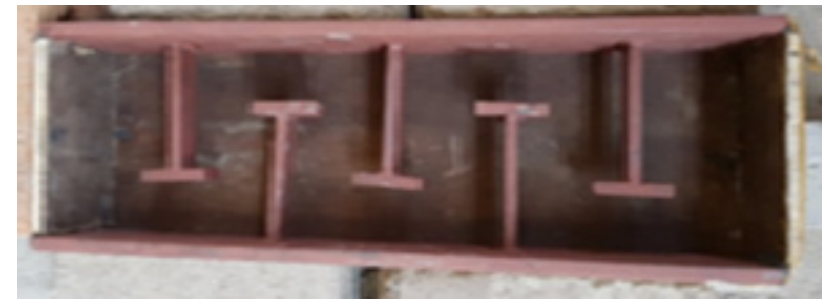

(d) Tee Connector

Figure 3. Steel flat plates welded with different types of connector for sandwich beam.

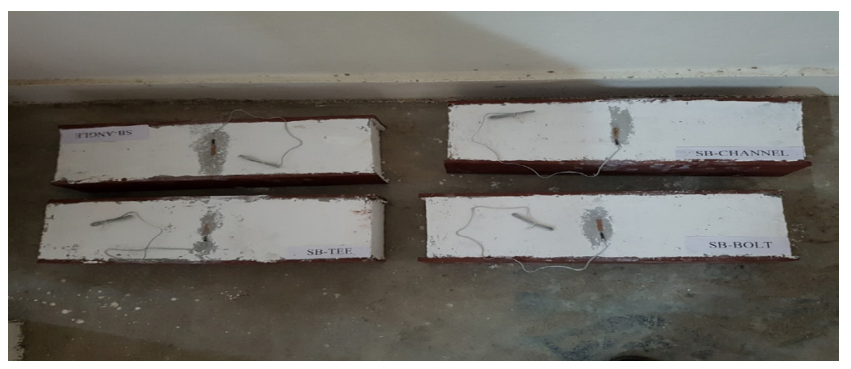

Figure 4. Sandwich beam before testing.

\section{Analytical Study}

The sandwich beams with different connectors were analysed using finite element software ANSYS. The modelling of the specimens was carried out using modelling software CATIA. The CATIA models were then imported to ANSYS to carry out the analysis. The element used for concrete is SOLID 65 and for steel is SOLID185 from the element library of ANSYS software. Figure 7 shows the mesh model of the steel part. Figure 8 shows the mesh model of the specimen.

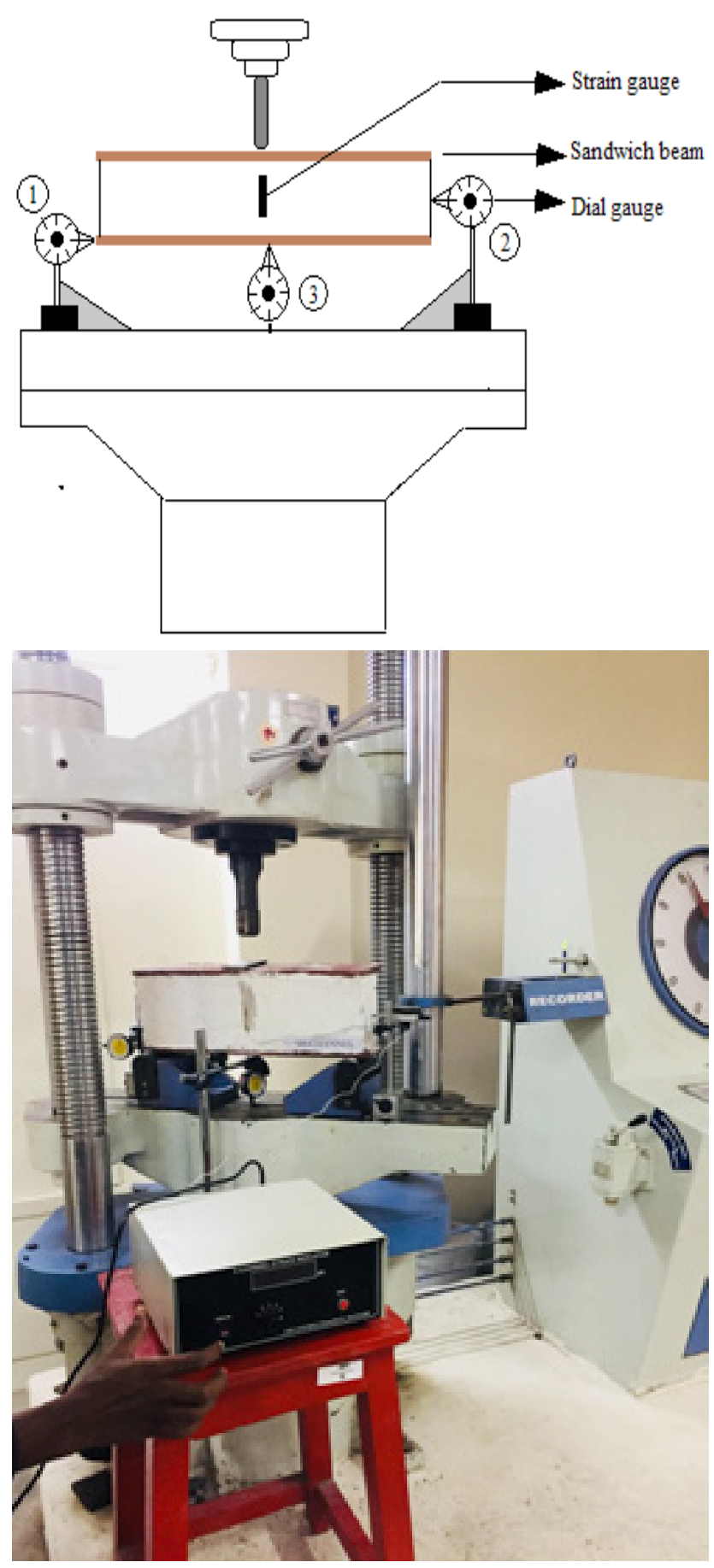

Figure 5. Testing of sandwich beam and position of the dial gauges. 


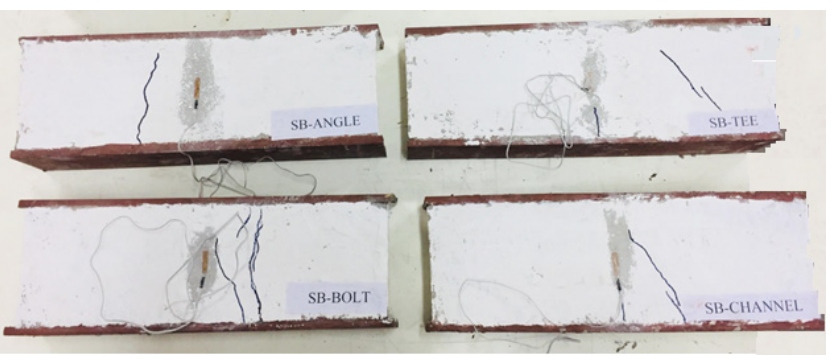

Figure 6. Sandwich beam after testing and its crack pattern.

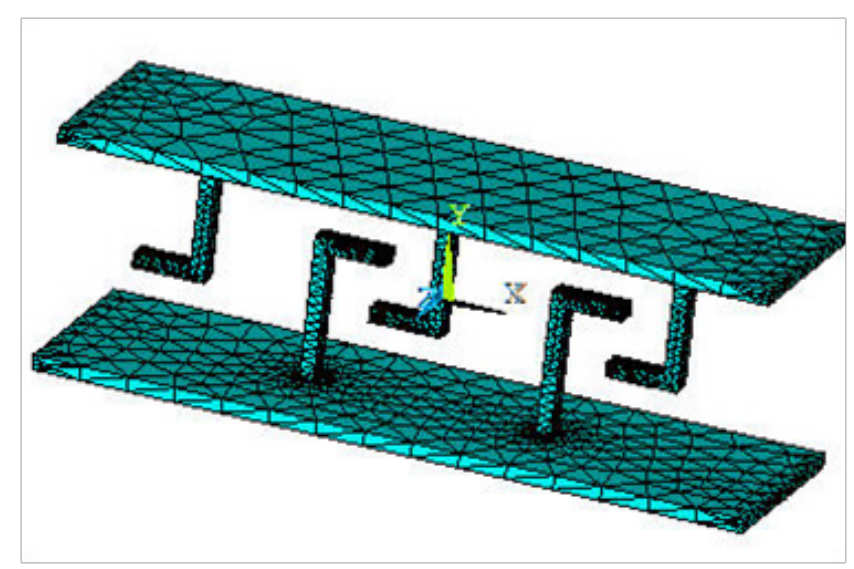

(a)Angle Connector

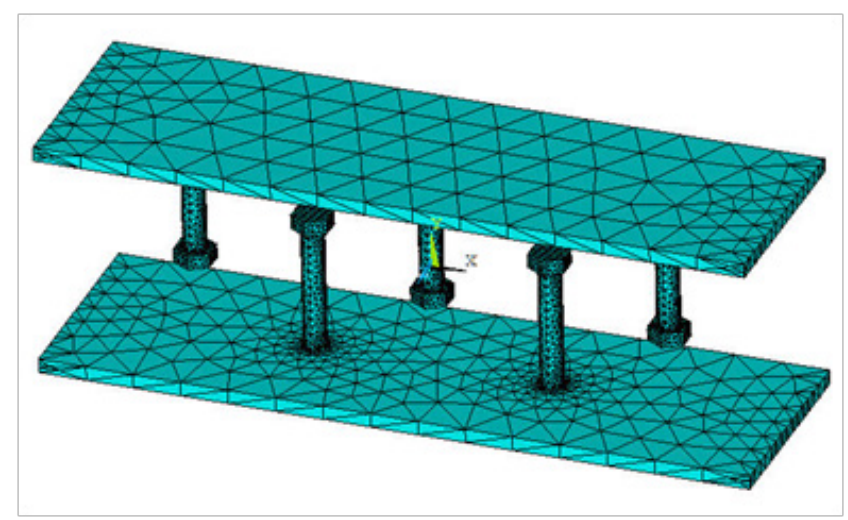

(b)Bolt Connector

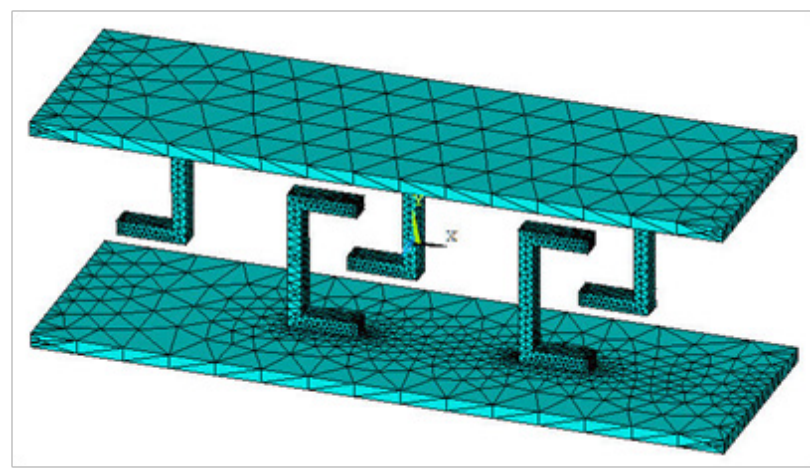

(c)Channel Connector

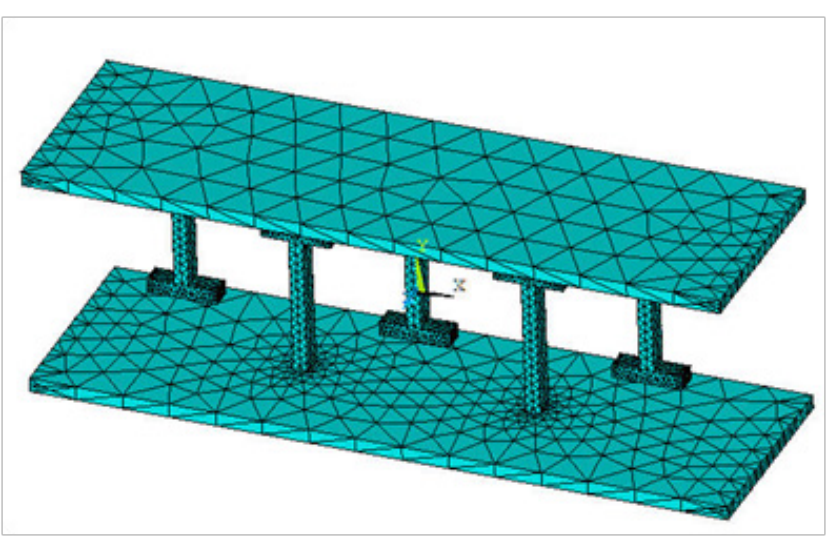

(d)Tee Connector

Figure 7. Mesh models of the steel connectors and flat plate used in sandwich beam using ANSYS.

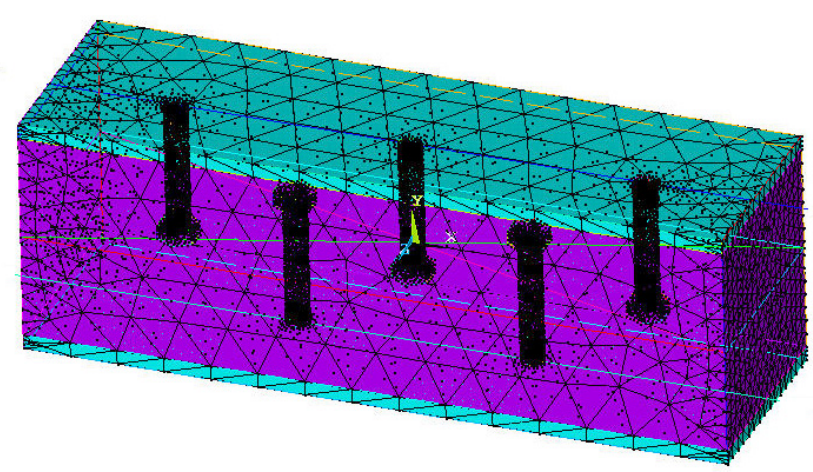

Figure 8. Model of sandwich beam with bolt connector.

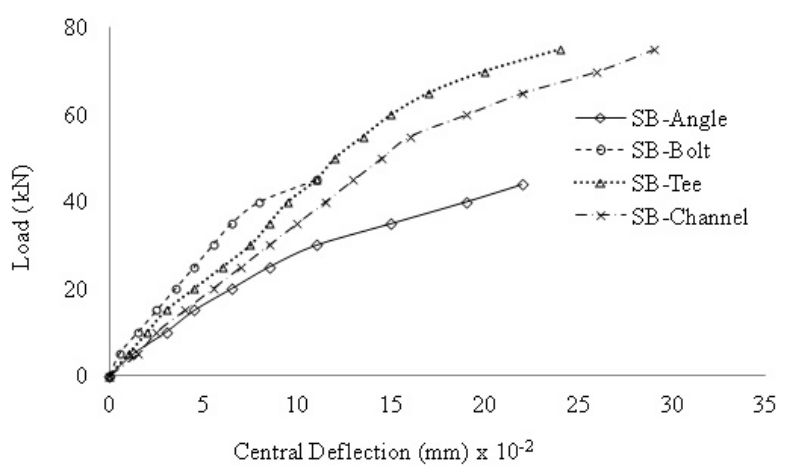

Figure 9. Load-Maximum central deflection of the specimens with different connectors.

\section{Result and Discussion}

\subsection{Load-Deflection Behaviour}

The load-deflection curves for the beams are plotted with the test results. All the beams showed almost linear load- 
deflection response up to $70 \%$ of the maximum load and became nonlinear with the gradual increase in the width of the cracks in the concrete core as load get increased. The load carrying capacity of the sandwich beam get improved by $65 \%$ in the beam having Tee and channel connectors when compared with the beam having L-angle and headed stud connector. The maximum deflection in the beam was between $0.25 \mathrm{~mm}$ and $0.30 \mathrm{~mm}$ for the sandwich beam with Tee and Channel connectors whereas for the beam with L-angle and headed stud connectors the maximum deflection observed between $0.11 \mathrm{~mm}$ to 0.22 $\mathrm{mm}$. Figure 9 shows the load-deflection plot for the sandwich beam with various shear connectors. The beam with Tee and Channel shear connectors deflects more than the beam with other connectors. The ductility behaviour was able to observe in the sandwich beam structure when compared to the normal RCC beam. In sandwich structures, the composite action between the steel plates and concrete are get influenced by the proper shear transfer mechanism andstrength of concrete.

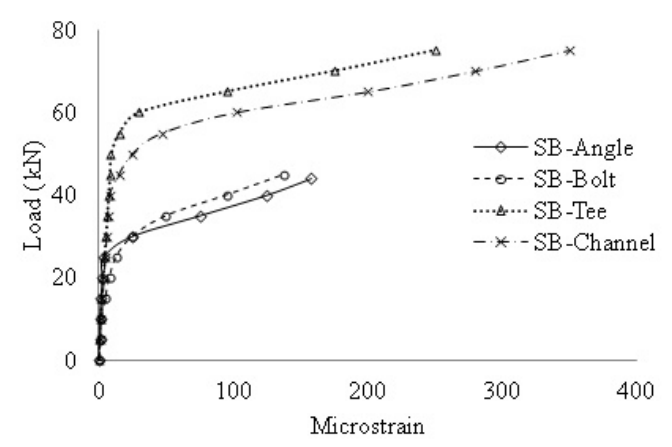

Figure 10. Load - strain behaviour of the sandwich beams with various shear connectors.

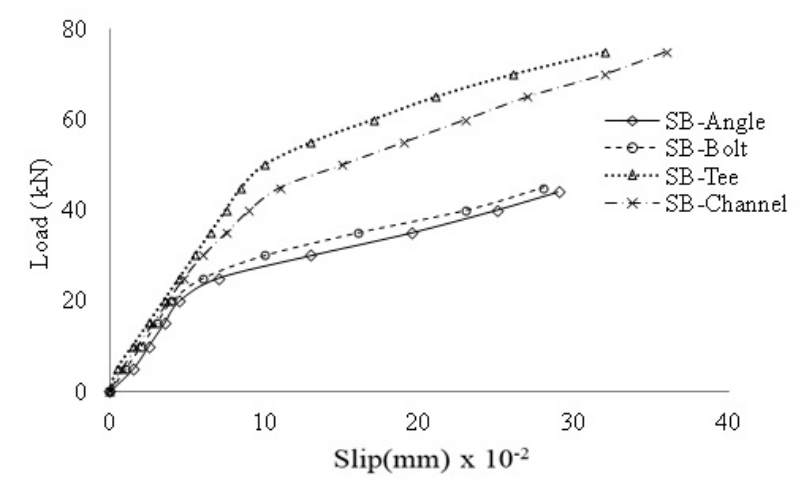

Figure 11. Load-slip curve of the sandwich beam for various shear connectors.

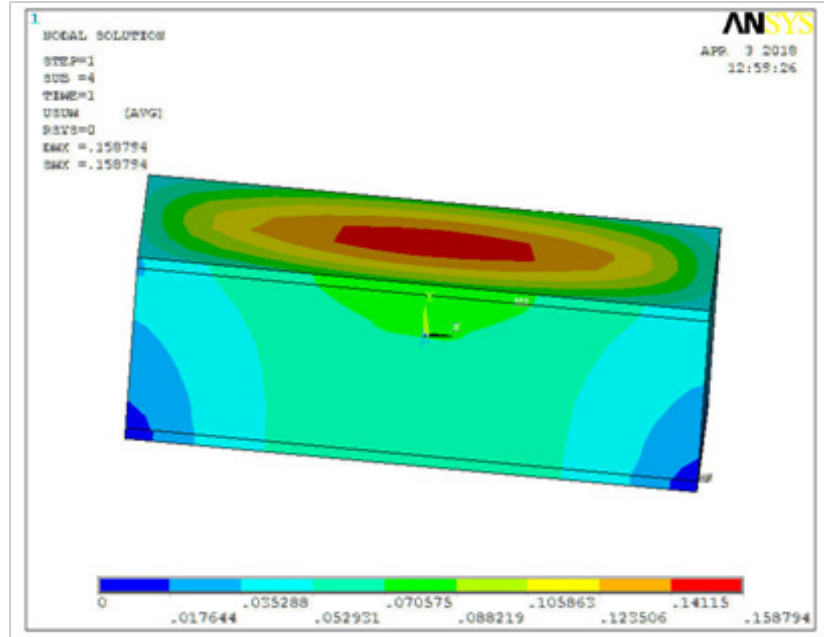

(a)SB-Angle Connector

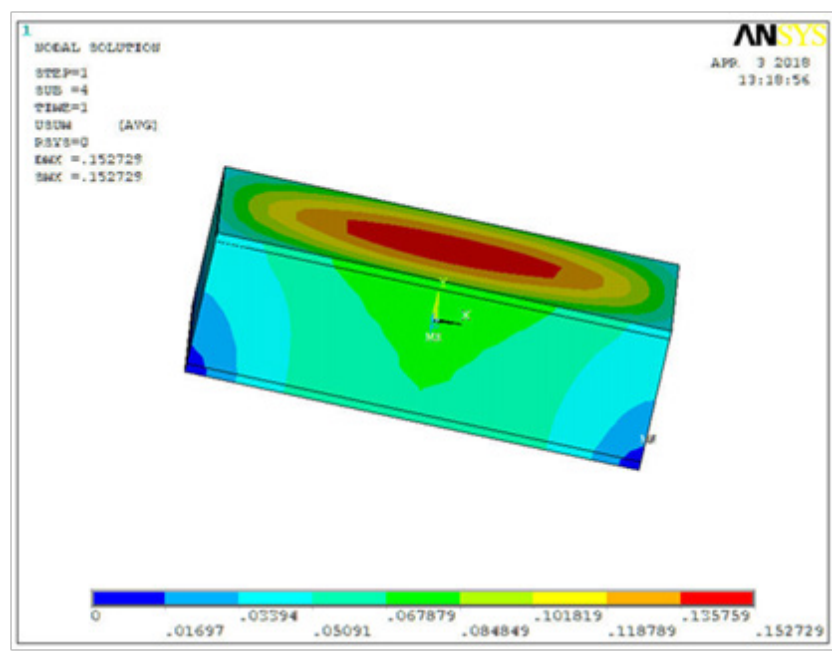

(b)SB-Bolt Connector

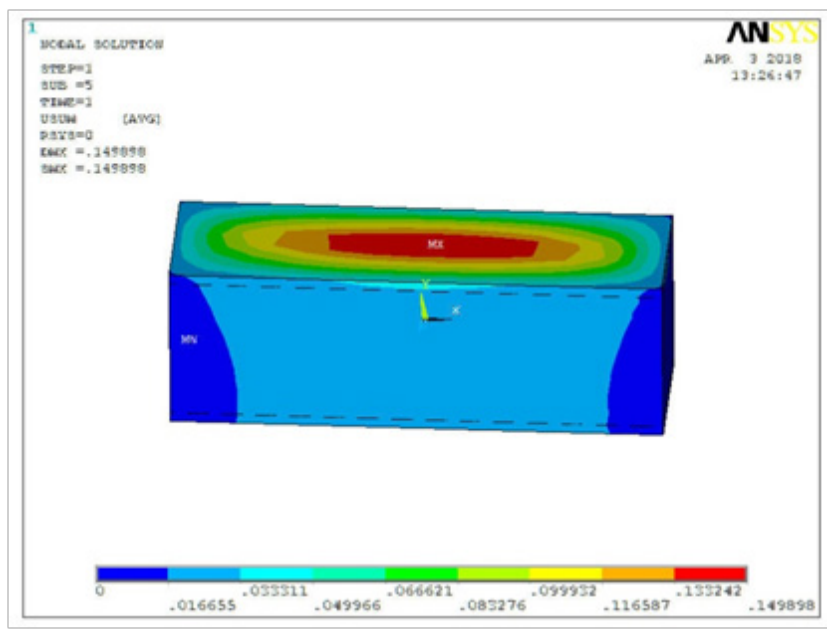

(c)SB-Channel Connector 


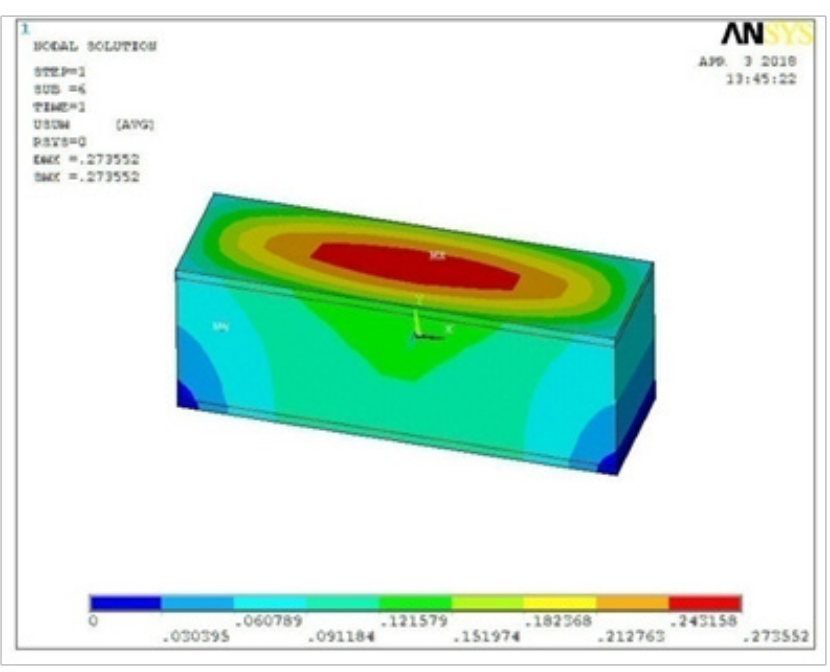

(d) SB-Tee Connector

Figure 12. Nodal displacement plot of sandwich beam with different connectors.

Table 2. Stiffness of the different shear connectors

\begin{tabular}{|l|l|l|}
\hline Sl.No & $\begin{array}{l}\text { Type of shear } \\
\text { connector }\end{array}$ & $\begin{array}{l}\text { Stiffness }(\mathbf{k}) \\
\text { N/mm }\end{array}$ \\
\hline 1 & Headed stud & 41,667 \\
\hline 2 & L-Angle & 40,000 \\
\hline 3 & Tee & 44,440 \\
\hline 4 & Channel & 50,000 \\
\hline
\end{tabular}

\subsection{Load-Strain Behaviour}

Figure 10 shows load versus strain plot of the steel concrete steel sandwich beam. SB-Channel and SB-Tee shows linear behaviour up to ultimate load and gradually increased up to the point of failure.

\subsection{Load-Slip Behaviour}

The stiffness of connectors ' $k$ ' can be determined from the load - slip plots. Figure 11 shows the load-slip plot between the outer steel plate and concrete core. From the Figure 11 the stiffness of the connectors was also found by taking the slope in the load-slip curves. Table 2 gives the stiffness values of the various connectors in $\mathrm{kN} / \mathrm{mm}^{2}$. From the plot it is clearly found that Tee and Channel connectors are stiffer than L-Angle and channel type of shear connector.

\subsection{Comparison between Experimental and Analytical Results}

The percentage difference between the experimental and analytical deflection is $11 \%$ irrespective of the types of connectors. This percentage variation shows that analytical model is slightly stiffer because of rigid connection. Figure 12 shows the nodal displacement plot of the sandwich beams with various connectors. From the plot it is observed that the sandwich beam with channel connectors is able to resist more load and deflected more than sandwich beam with other connectors.

The Table 3 lists the analytical values obtained from ANSYS and corresponding experimental values

\section{Conclusions}

The experimental study was carried out on steel concrete steel sandwich beam for the various shear connectors such as Headed stud, L-Angles, Tee sections and channel sections under flexural loading. The number of connectors on the three and two on the loading face and the support face respectively. The load-strain, load-deflection and load-slip behaviour was also studied. The analytical study was also carried out using ANSYS to compare the results. The conclusion arrived from the study are.

- The sandwich beam with Tee and channel connectors shows better performance in term of

Table 3. Comparison between experimental and analytical results

\begin{tabular}{|c|c|c|c|c|c|}
\hline \multirow[t]{2}{*}{ Sl. No } & \multirow{2}{*}{$\begin{array}{l}\text { Detail of } \\
\text { specimen }\end{array}$} & \multicolumn{2}{|c|}{ Experimental Results } & \multicolumn{2}{|c|}{ Analytical Results } \\
\hline & & $\begin{array}{l}\text { Max } \\
\operatorname{load}(k N)\end{array}$ & $\operatorname{Max}$ Deflection $(\mathrm{mm})$ & $\operatorname{Max} \operatorname{load}(\mathrm{kN})$ & $\operatorname{Max}$ Deflection(mm) \\
\hline 1 & SB-Bolt & 45 & 0.11 & 45 & 0.10 \\
\hline 2 & SB-Angle & 44 & 0.22 & 44 & 0.18 \\
\hline 3 & SB-Channel & 75 & 0.29 & 75 & 0.25 \\
\hline 4 & SB-Tee & 104 & 0.21 & 104 & 0.19 \\
\hline
\end{tabular}


load by $65 \%$ when compared with the beam having L-angle and headed stud connector.

- The maximum deflection in the beam was observed in the beam with Tee and Channel connectors are $0.25 \mathrm{~mm}$ and $0.30 \mathrm{~mm}$ respectively whereas for the beam with L-angle and headed stud connectors, the maximum deflection observed was between $0.11 \mathrm{~mm}$ to $0.22 \mathrm{~mm}$.

- In sandwich structures, the composite action has been enhanced by means of providing proper shear transfer mechanism between the face plates.

- The stiffness of the C-Connectors and Tee connectors was found to be $45,000 \mathrm{~N} / \mathrm{mm}^{2}$ and for stud and L-angle it was between $40,000 \mathrm{~N} / \mathrm{mm}^{2}$ to $41,000 \mathrm{~N} / \mathrm{mm}^{2}$.

- The percentage decrease in the deflection observed in the sandwich beam is $11 \%$ for change from experimental to analytical values.

- The analytical model is stiffer than the experimental model due to rigid connectors between steel plate, shear connectors and concrete.

- The comparisons between experimental and analytical results for sandwich beams with different connector shows that analytical model is stiffer and sandwich beam with channel connectors deflects more. The sandwich beam with channel connectors able to resist more loads.

\section{References}

1. Daniel IM, Abot JL. Fabrication, testing and analysis of composite sandwich beams. Composite Science and Technology. 2000; 60(12-13):2455-63. https://doi. org/10.1016/S0266-3538(00)00039-7

2. Foundoukos N, Chapman JC. Finite element analysis of steel-concrete-steel sandwich beams. Journal of Constructional Steel Research. 2008; 64(9):947-61. https:// doi.org/10.1016/j.jcsr.2007.10.011

3. Richard LJY, Sohel KMA. Lightweight steel-concrete-steel sandwich system with J-hook connectors. Engineering Structures. 2009; 31(5):1166-78. https://doi.org/10.1016/j. engstruct.2009.01.013

4. Dia XX, Richard LJY. Fatigue performance of lightweight steel - concrete - steel sandwich systems. Journal of Constructional Steel Research. 2010; 66(2):256-76. https:// doi.org/10.1016/j.jcsr.2009.07.009

5. Sohel KMA, Richard LJY. Steel-Concrete-Steel sandwich slabs with lightweight core - Static performance. Engineering Structures. 2012; 33:981-92. https://doi. org/10.1016/j.engstruct.2010.12.019

6. Sohel KMA, Richard LJY, Yan JB, Zhang MH, Chia KS. Behavior of steel-concrete-steel sandwich structures with lightweight cement composite and novel shear connectors. Composite Structures. 2012; 94:3500-09. https://doi. org/10.1016/j.compstruct.2012.05.023

7. Yu-Bing L, Xiao-Bing S, Meng C, Hong-Hui G. Experimental Study and Theoretical Analysis of Resistance of SteelConcrete-Steel Sandwich Beams. Journal of Structural Engineering. 2015; 141(2):1-11.

8. Sangeetha P, Senthil R. A study on ultimate behaviour of composite space trusses. KSCE Journal of Civil Engineering. 2017; 21(3):950-4. https://doi.org/10.1007/ s12205-016-0920-8 